\title{
Simulation modeling balancing current in the traction network of a substation group
}

\author{
Valerij $\mathrm{Li}^{1}$, and Yuliya Konstantinova, ${ }^{1, *}$ \\ ${ }^{1}$ FESTU, Institute of Power Engineering, 680021 Serysheva st. 47, Khabarovsk, Russia
}

\begin{abstract}
This article is devoted to assessing the transit of electricity from an external electrical power supply system through the traction network of a railway district that includes nine traction substations. Substation transformers has star-delta-11 connection. The paper presents a simulation model of the railway district implemented in the MATLAB/Simulink software package. Various options of loading the external power supply system are modeled including into account the symmetrical load of the external network and the single-phase load of traction substations. The values of the voltage difference on the traction windings of power transformers of adjacent substations that occurs at different loads, the balancing currents that this difference creates and real power losses in the inter-substation areas are calculated.
\end{abstract}

\section{Introduction}

At present, the volume of traffic on the Far Eastern Railway of the Russian Railways branch is increasing and their implementation requires the strengthening of the traction power supply system, which, as a rule, leads to a decrease in the resistance of the traction network and helps to increase the flow of electricity from the external power supply system to the traction system. When the traction network works together with the external power supply system, a balancing current (BC) occurs in the traction network. This current flowing through the elements of the network creates additional energy losses. Thus, the energy indicators of the electrified railway are reduced, and Russian Railways Company incurs economic damage from imperfections in the interfacing of external and traction power supply systems. Some disadvantages in the joint operation of the external power supply system with the traction network are caused by the simultaneous electrification of the railway and settlements, industrial and agricultural loads in the regions [1-3].

There are the following causes of the equalizing current:

- Several identical traction substations (TS) are connected to the same line,

- A low power transformer is installed on one of the TSs,

- A double transformation is applied at one of the TSs (transformation from 220 to $110 \mathrm{kV}$ by autotransformer and from 110 to $27.5 \mathrm{kV}$ by transformer),

- Adjacent TSs are powered by networks of various voltage classes,

- The TSs group receives power from a power system with a voltage class of $220(110) \mathrm{kV}$, and one of the TSs receives power from a distribution substation with a voltage of $110(220) \mathrm{kV}$,

- The third winding of the traction transformer TS is supplying a powerful load.

Three-phase transformers in which the star-delta-11 connection supplies two inter-substation areas (ISA) each with a separate phase. As a result, the operating rate for the phases, are significantly different. The third phase of the external power supply network is underloaded and to reduce asymmetry when each subsequent substation is connecting to the network, the underloaded phase is alternated. Thus, as a rule, the same ISA is simultaneously powered by the leading phase of one of the adjacent substations and the lagging phase second substation. Voltage losses in the traction windings of transformers that supply ISA with the leading and lagging phase are determined by the formulas:

$$
\begin{gathered}
\Delta \bar{U}_{\text {lead }}=\frac{2}{3} \cdot I_{\mathrm{r} 1} \cdot X_{1}^{\prime} \cdot \sin \varphi_{\mathrm{r} 1}-\frac{1}{3} \cdot I_{11} \cdot X_{1}^{\prime} \cdot \sin \left(60-\varphi_{11}\right) \\
\bar{U}_{\text {lagg }}=\frac{2}{3} \cdot I_{l 2} \cdot X_{2}^{\prime} \cdot \sin \varphi_{l 2}+\frac{1}{3} \cdot I_{r 2} \cdot X_{r 2}^{\prime} \cdot \sin \left(120-\varphi_{r 2}\right),
\end{gathered}
$$

where $I_{\mathrm{r}}, I_{11}$ is the magnitude of current phasor on the right and left ISA for the first substation, $A ; \varphi_{r 1}, \varphi_{11}$ is the power-factor angle on the right and left ISA for the first substation, electrical degrees; $I_{\mathrm{r} 2}, I_{12}$ is the magnitude of current phasor on the right and left ISA for the second substation, $\mathrm{A} ; \varphi_{\mathrm{r} 2}, \varphi_{12}$ is the power-factor angle on the right and left ISA for the second substation, electrical degrees; $X_{1}^{\prime}, X_{2}^{\prime}$ is the equivalent inductive reactance of the external power supply system and the transformer for the first and second substation, Ohm. As can be seen from the formulas, even with equal loads in the right and

* Corresponding author: kamfes@mail.ru 
left ISA, voltage losses in the lagging phase will be higher than in the leading phase.

The purpose of the research is to evaluate the flow of electric energy amount from an external electrical power supply system through an AC traction network on a railway district. The objectives of the research are, firstly, a creating a simulation model of the power supply system of an electrified railway district, secondly, simulating the flow of electricity with various load cases of the power supply system; thirdly, assessing the effect of power-factor correction units and series capacitor banks on the flow of electricity through the traction network; fourthly, assessing the effectiveness of measures to reduce balancing current.

\section{Power supply system simulation}

The considered electrified railway district includes 9 traction substations (Fig.1). Substations No. 1-2, 5-9 are connected to a network voltage of $220 \mathrm{kV}$, substation No. 4 receives power from a network voltage of $110 \mathrm{kV}$. Substation No. 1 receives electricity mainly from the adjacent power supply system (S1), substation No. 2 is connected to buses $220 \mathrm{kV}$ of the system-forming substation with a higher voltage of $500 \mathrm{kV}$ (S2). Substations No. 3 and 4 receive electricity from power supply sources S3-S5. A group of substations consisting of No. 5-9 is connected to a double-circuit line $220 \mathrm{kV}$ which connects power supply sources S5 and S6. The data on the voltages supplying the inter-substation areas are presented in table 1 .

Table 1. The data of the inter-substation areas voltages.

\begin{tabular}{|c|l|l|}
\hline ISA & Phase voltage & $\begin{array}{l}\text { Type phase voltage for the } \\
\text { substation left/ right }\end{array}$ \\
\hline $1-2$ & $\mathrm{U}_{\mathrm{B}}$ & lagging / leading \\
\hline $2-3$ & $\mathrm{U}_{\mathrm{C}}$ & lagging/lagging \\
\hline $3-4$ & $\mathrm{U}_{\mathrm{B}}$ & leading /lagging \\
\hline $4-5$ & $\mathrm{U}_{\mathrm{A}}$ & leading /lagging \\
\hline $5-6$ & $\mathrm{U}_{\mathrm{C}}$ & leading /leading \\
\hline $6-7$ & $\mathrm{U}_{\mathrm{A}}$ & lagging / leading \\
\hline $7-8$ & $\mathrm{U}_{\mathrm{B}}$ & lagging / leading \\
\hline $8-9$ & $\mathrm{U}_{\mathrm{C}}$ & lagging/lagging \\
\hline
\end{tabular}

Power-factor correction units (PFCU) are installed at traction substations No. 1-3, 5-7 and 9. Series capacitor banks (SCB) are connected between the rail and the output of the transformer winding $27.5 \mathrm{kV}$ at substations No. 4 and 8. This study used simulation in the MATLAB / Simulink software package [4,5].

The following blocks were used when creating the model:

- The three-phase source block as power supply sources and system-forming substations (S1-S6),

- The pi section line as overhead high-voltage line section,

- The three-phase transformer as a transformer of the external network (220/110) and traction substation (220 (110) / 27.5),

- The series RLC branch as section of the traction network (overhead line $25 \mathrm{kV}$ and a rail circuit),
- The three-phase series RLC load as symmetric three-phase load (L1, L2),

- The series RLC load as point traction load (40 MVA).

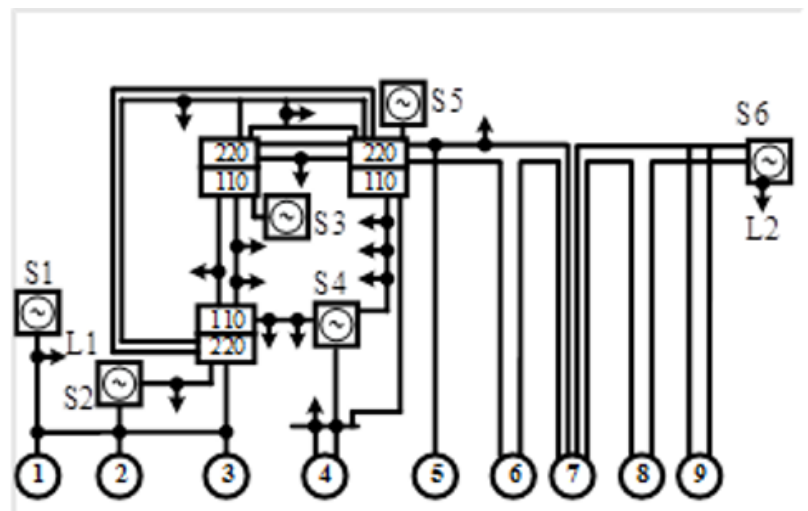

Fig. 1. Electrical power supply system of the electrified railway district.

\subsection{Simulation options}

The following options for loading the external network were simulated:

- Only symmetrical three-phase load in the network (Fig. 1 indicated by blocks L1 and L2) at rated currents in the wire on sections S1-1 and S5-5, when the PFCUs and SCBs are disconnected (op1),

- Only symmetrical three-phase load in the network at rated currents in the wire on sections S1-1 and S5-5, when and SCBs are enabled the PFCUs are disconnected (op2),

- Only symmetrical three-phase load in the network at rated currents in the wire on sections S1-1 and S5-5, when and SCBs are disconnected the PFCUs are enabled (op3),

- Only symmetrical three-phase load in the network at half of rated currents in the wire on sections S1-1 and S5-5 (the PFCUs and SCBs are disconnected) (op4),

- Symmetrical three-phase load in the network at half of rated currents in the wire on sections S1-1, S5-5 and the traction load for all ISAs except for the ISA under consideration (the PFCUs and SCBs are disconnected) (op5).

\subsection{Simulation results}

The results of simulation the balancing current that occurs in the traction network with the above-described load variants of the external system are presented in table 2.

The flow of electric energy from the external electrical power supply system through the traction network is minimum value at the ISAs 2-3 and 3-4, which can be explained by the location of these substations at the near the power supply sources. The maximum value of the $\mathrm{BC}$ for all the simulation options is at the area inter substation No. 6 and 7, which is also 
due to the most remote location of them from the power supply sources.

Table 2. Results of calculating the balancing current.

\begin{tabular}{|c|c|c|c|c|c|}
\hline \multirow{2}{*}{ ISA } & \multicolumn{6}{|c|}{ Balancing current, A } \\
\cline { 2 - 6 } & op1 & op2 & op3 & op4 & op5 \\
\hline $1-2$ & 120.9 & 121.0 & 119.2 & 60.9 & 89.3 \\
\hline $2-3$ & 2.5 & 3.6 & 3.0 & 9.9 & 9.4 \\
\hline $3-4$ & 16.2 & 34.9 & 10.7 & 11.8 & 31.5 \\
\hline $4-5$ & 129.0 & 158.0 & 110.4 & 62.9 & 111.6 \\
\hline $5-6$ & 139.8 & 139.9 & 140.1 & 60.4 & 69.1 \\
\hline $6-7$ & 167.1 & 168.5 & 175.7 & 73.9 & 87.2 \\
\hline $7-8$ & 121.6 & 139.2 & 131.2 & 52.6 & 70.7 \\
\hline $8-9$ & 131.8 & 139.1 & 126.4 & 57.0 & 47.9 \\
\hline
\end{tabular}

The resistance of the two adjacent inter-substation areas decreases when the SCB is switched on at the substation located in the middle. At the same time, the balancing current increases by $11-31 \%$ at areas that receive power from the TS No. 8. An increase in surge current amounted to $50 \%$ for the area located to the right of substation No. 4 and almost $400 \%$ for the ISA posted to the left.

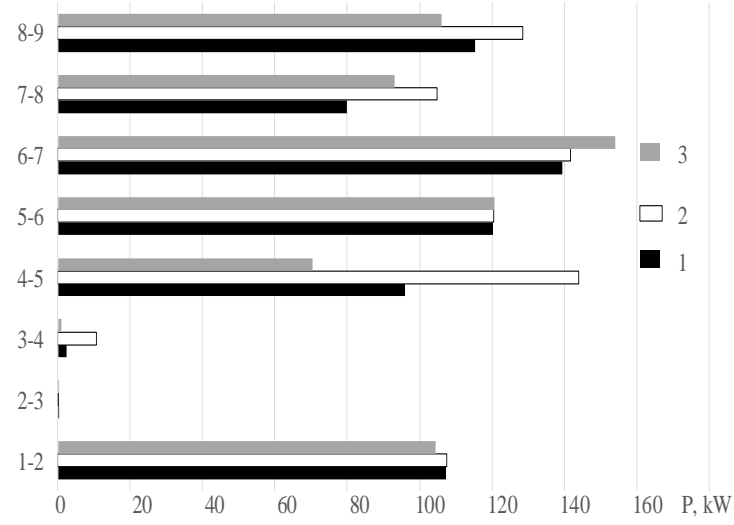

Fig. 2. Bar chart of the real power losses for options 1-3.

The use of PFCUs mainly reduced the balancing current at the inter-substation areas 1-2 (1.4\%), 3-4 $(34 \%), \quad 4-5 \quad(14 \%)$ and 8-9 (4\%), however, overcompensation caused current a $\mathrm{BC}$ increase at the ISAs 2-3 (17\%), 5-6 (0.2\%), 6-7 (5\%) and 7-8 (8\%). The real power losses of the options considered are presented in Fig. 2. The application of the SCB s leads to a general increase in real power losses at the areas by $15 \%$, while losses when turning on PFCUs are reduced by $1.4 \%$.

Real power losses increase at all inter-substation areas (fig.3), when the external network load combines a symmetrical three-phase and traction load (options 5), the exception is the inter-substation area 8-9 because substations supply this ISA by lagging phases. In this case, the voltage losses caused by the flow of the traction load of adjacent ISAs have the effect of equalizing the voltage on the buses of these substations (the same effect is at ISA 2-3).

The voltage difference at ISA 1-2, which is supplied simultaneously by the leading and lagging phase, increases, because the voltage loss is higher at TS No.1. Real power losses are significantly increased at ISA 4-5, because load losses at TS No. 5 are higher (lagging phase) than at TS No. 4 (leading phase). Real power losses in the inter-substation area 3-4 are small compared to the others, since this zone is the longest in the section, its length is $62.7 \mathrm{~km}$ (the shortest zone between substations 4 and 5 is $38.2 \mathrm{~km}$ long). Based on the calculation results, it is recommended to take measures to reduce the balancing current in the traction network in the ISA 1-2, 4-5, 5-6, 6-7, 7-8 and 8-9.

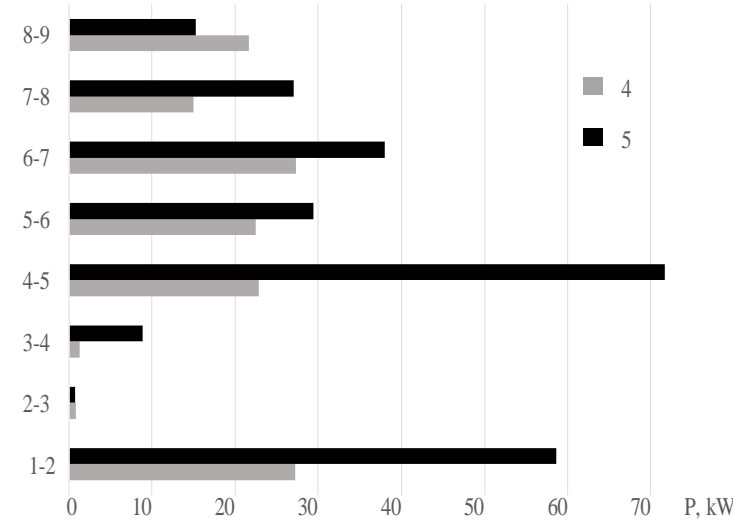

Fig. 3. Bar chart of the real power lose for options 4 and 5 .

\section{Modeling of measures to reduce balancing current}

The following measures to reduce $\mathrm{BC}$ are simulated:

- relocation of the substation`s No. 4 neutral section,

- grid reconnection of traction substations transformers,

- application of a booster transformer at ISAs 1-2, 4$5,5-6,6-7,7-8$ and 8-9.

\subsection{Relocation of the neutral section}

The simulation of the TS No. 4 neutral section relocation $12 \mathrm{~km}$ closer to TS No. 3 showed a decrease in the balancing current at the ISA $4-5$ by $19 \mathrm{~A}$, while increasing the $\mathrm{BC}$ at the ISA $3-4$ is $2 \mathrm{~A}$. The total power loss in two ISAs decreased $8-10 \%$, depending on the option, losses on the entire district from this event decreased by $2-3 \%$.

\subsection{Grid reconnection of traction substations transformers}

As mentioned above the third phase of the external power supply network is underloaded and to reduce asymmetry when each subsequent substation is connecting to the grid, the underloaded phase is alternated. In the considered electrified railway district, the alternation of the underloaded phase is as follows: $\mathrm{C}$ A-A-C-B-B-C-A-A. The study simulated the work of the power supply system when changing grid reconnection of transformers at traction substations No. 3 -5 and 9, which led to the alternation of the underloaded phase $\mathrm{C}$ A-B-C-A-B-C-A-C. Simulation of the grid reconnection of traction substations transformers revealed a $\mathrm{BC}$ decrease when the network supplies only a symmetric 
three-phase load (options 1 and 4) by 1-2\%. Balancing current decreased at the ISA 3-4 by 28 A but increased at other areas by 2 to $39 \mathrm{~A}$, which led to a rise in total losses by $13 \%$ when the network supplies a symmetric three-phase and traction load.

\subsection{Application of a booster transformer}

The most effective way to reduce the flow of electricity from the external electrical power supply system through the traction network is to equalize the voltage on the $27.5 \mathrm{kV}$ buses of adjacent TSs. In Fig. 4 shows a bar chart value geometric $|\Delta \bar{U}|$ and algebraic $|\bar{U} 1|$ $|\overline{\mathrm{U}} 2|$ of the ISAs voltage difference have been calculated for option 4 and 5 .

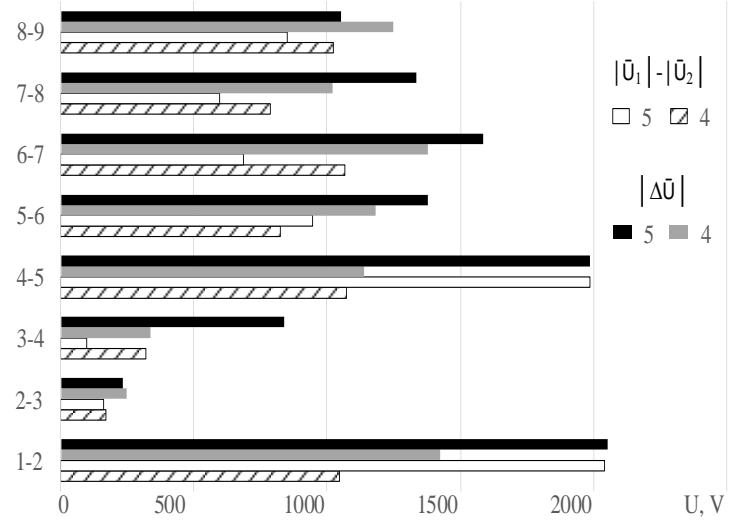

Fig. 4. Bar chart value geometric $|\Delta \overline{\mathrm{U}}|$ and algebraic $|\overline{\mathrm{U}} 1|$ $|\overline{\mathrm{U}} 2|$ of the voltage difference for option 4 and 5 ..

As can be seen from the bar chart, these differences usually differ by an average of $20-30 \%$, so equalization of the voltage on-load tap-changer will be ineffective [1, 6]. An automatic balancing current reduction device is proposed [1], which consists of a block of voltage addition and contains an input transformer, an rectifier $[7,8]$, a voltage inverter, a rectifier filter, an output filter [9] and a voltage-boosting transformer [3]. The additional voltage is formed as follows. The input transformer steps down traction network voltage to the rated voltage of the rectifier. Then, after rectification and filtering, a DC voltage is applied to the input of the inverter. Meanwhile, the control unit receives data from phasor measurements units [10] of the adjacent TSs and calculates the angle and magnitude of the additional voltage. Next, control signals are sent to the inverter to generate a voltage with pulse width modulation [11]. After filtering the sinusoid with a frequency of $50 \mathrm{~Hz}$ and with an angle of additional voltage, it is fed to the primary winding of the booster transformer. Thus, an additional voltage is formed on the secondary winding of the BT:

$$
\Delta \bar{U}_{b}=-\Delta \bar{U}=-\left(\bar{U}_{1}-\bar{U}_{2}\right)=\frac{\bar{U}_{i n} \cdot K_{r} \cdot H \cdot K_{T 2}}{K_{T 1}},
$$

where $\bar{U}_{1}, \bar{U}_{2}$ is the voltage phasors on the buses of adjacent substations, $\mathrm{kV} ; \bar{U}_{\text {in }}$ is the input voltage, $\mathrm{kV}$;
$K_{\mathrm{T} 1}$ is the input step-down transformer ratio; $K_{\mathrm{r}}$ is the ratio between the rectified and the alternating voltage; $H$ is switching functions of PWM inverter, representing closed states of inverter semiconductors; $K_{\mathrm{T} 2}$ is booster transformer ratio.

The use of a device with a booster transformer reduced the losses of electricity traction network by $97 \%$.

\section{Conclusions}

Firstly, it was found that the use of series capacitor banks significantly increases the flow of electricity from an external power supply system through the traction network. Secondly, the traction load of other intersubstation areas flows through the inter-substation areas, on which there are no electric locomotives. Thirdly, the balancing current rises due to the one inter-substation area is powered by both the leading and the lagging phase at the same time. Finally, the most effective measure to reduce the flow from the external network to the traction network is to install booster devices.

\section{References}

[1] Y.A. Konstantinova, V.N. Li, A.M. Konstantinov, International Scientific Siberian Transport Forum TransSiberia 2019: VIII International Scientific Siberian Transport Forum 1115, 15-24 (2020)

[2] Y.A. Konstantinova, V.N. Li, E.Y. Tryapkin, 2018 International Multi-Conference on Industrial Engineering and Modern Technologies (FarEastCon), IEEE Press, 1-5 (2018)

[3] A.B. Kosarev, B.I. Kosarev, Russian Electrical Engineering 89, 9, 531-535 (2018)

[4] U.J. Shenoy, K.G. Sheshadri, K. Parthasarathy, H.P. Khincha, D. Thukaram, 2004 IEEE Region 10 Conference TENCON, IEEE Press, Chiang Mai 3, 508-511 (2004)

[5] G.B. Worku, A.B. Kebede, Global Energy Interconnection 1, 2, 187-196 (2018)

[6] X. Zhang, R. Kang, M. McCulloch, A. Papachristodoulou, Sustainable Energy, Grids and Networks 5, 27-38 (2016)

[7] S.S. Moolamkunnam, J. Mathew, S. Joseph, International Journal of Innovative Research in Electrical, Electronics, Instrumentation and Control Engineering 7, 4, 50-58 (2019)

[8] N.A. Samsudin, D. Ishak, A.B Ahmad, Engineering Science and Technology 21, 2, 189200 (2018)

[9] M. Pomalis, R.C. Leborgne, A.R. HerreraOrozco, A.S. Bretas, Electric Power Systems Research 176, 1-9 (2019)

[10] S. Affijulla, P. Tripathy, Protection Applications, IEEE Transactions on Smart Grid 9, 2, 12501260 (2016)

[11] D.G. Holmes, Power Converters Principles and Practice, John Wiley \& Sons, Inc., 155-214 (2003) 